\title{
Your Smartphone, my Smartphone - How Smartphone Ownership determines Social Group Affiliation
}

\author{
Sören Diel \\ University of Bayreuth \\ soeren.diel@uni-bayreuth.de
}

\author{
Christoph Buck \\ University of Bayreuth \\ christoph.buck@uni- \\ bayreuth.de
}

\author{
Torsten Eymann \\ University of Bayreuth \\ torsten.eymann@uni- \\ bayreuth.de
}

\begin{abstract}
Smart mobile devices have arrived in the center of our society and provide multiple support in users' daily life. With the mass adoption of smart mobile devices social life changed dramatically. In which way the used smartphone has impact on the perceived group affiliation is not investigated yet. This paper provides a first step in observing the membership of users to their smartphone group. The decision regarding the purchase of a smartphone has extensive consequences of the technological future of users. They lock-in to a system which determines multiple future decisions. The chosen system describes an important technological path dependency. This paper presents a study investigating the rivalry between different smartphone groups. The results show differences between the levels of identification of users with their smartphone manufacturers. Moreover, the results show that for smartphone users it depends on their smartphone manufacturer, which factors are important for a rivalry.
\end{abstract}

\section{Introduction}

With the mass adoption of personal computers, notebooks, and predominantly smart mobile devices (SMD) like smartphones and tablets the average user of information systems (IS) has dramatically changed [1]. Disruptive innovations like the iPhone, the iPad, and software in form of mobile applications (apps) diffused into the everyday life of users. Apps are integral to the functioning of SMD and are key elements for the interface design and functionality. SMD and apps are the logical consequence of experiential computing: the "digitally mediated embodied experiences in everyday activities through everyday artefacts that have embedded computing capabilities" [1]. These modern IS are used to perform every kind of task and users benefit while handling their everyday routine. Everyday activities are almost 'naturally' carried out or supported by SMD and apps, or as Apple puts it in one of their slogans: "There's an app for that ${ }^{\circledR} "$ [2] - which addresses the broad scope of todays IS are used for.

In all objectivity, it is irrelevant which system is chosen by the user to perform her everyday tasks. The two market leaders for mobile ecosystems, Apple and Google, provide their operating systems (OS) for about $99 \%$ of the global market [3]. From the perspective of the goal-oriented need satisfaction, their service portfolio is quite the same. Both of them support an extensive software-development kit (SDK) which enables 3rd-party developers to provide every kind of app. Thereby, Apple and Google established a very robust business model by attracting millions of developers on the one hand and millions of users on the other hand. Thus, the 3rd-party developers gain a large share of the value the OS-providers offer with their system. This leads to enormous entry barriers for new competitors. As a consequence, two market-dominating mobile ecosystems evolved and are integrated by the majority of smartphone manufacturers.

Taking this market situation into account, it is a strategic question why users adopt one particularly smartphone, why they continually are faithful to the device manufacturer and the underlying ecosystem, and why they switch the device manufacturer or the ecosystem. These questions are important for the understanding of the buying behavior of smartphone users and their decision regarding the system they use in everyday life.

With the mass adoption of SMD and apps, this selection determines a vast number of users' future decisions. They initiate a path dependency regarding software products (apps) which they use about 88 times a day [4]. This deep everyday life integration of the IS established a new relationship between users and technology. Today, users are highly dependent on their smartphone, they bank on the support of their device in everyday life, they build up emotional relationships with their devices, and they are at risk in getting addicted by the use of their smartphone [5]. With an increasing integration of technology in everyday life and the 
apparent interaction of the used technology, users begin to treat smartphones as social actors (media equation) [6]. Sarwar and Soomro [5] point out tremendous impacts of smartphones in the fields of business, education, health, psychology, and social life. Consequently, the usage of smartphones has a huge impact on the social life on users in a positive and negative way [5]. Current research shows, that smartphone usage is associated with personality traits [7], and that the purchase behavior of users is related to smartphones [8].

Thus, smartphones do have a huge impact on the social life and society. The usage of a system and a particular device manufacturer determines the belongingness to a social group [9]. This leads to the finding that users chose their SMD or mobile system based on their personal and social identity.

In this paper we investigate the inside-out groupperspective of users regarding their SMD-affiliation. We assume that users distance themselves from other user groups because of the device they use. We provide a survey-based study concerning the rivalry between smartphone users. With the provided study we investigate the following research question:

Does the ownership of a smartphones determine the perceived group affiliation?

To answer this research question, the remainder of this article is structured as follows. In the following section the theoretical foundations and relevant work of the Social Identity Theory, of Rivalry, and its implications to IS are discussed. In section 3 we apply the chosen research method to the field. Subsequently, we present the results of the study and discuss the main findings. Finally, a conclusion is provided containing limitations, implications and future research.

\section{Theoretical background}

\subsection{Social identity theory}

Tajfel and Turner's [10] Social-Identity Theory (SIT) states that individuals' behavior is determined by their personal and their social identity.

While the personal identity is determined by the individual's characteristics and behaviors, the social identity is defined by the memberships of an individual in social groups. Social groups are "more than two people who share the same social identity" [11]. Personal and Social Identity are the two fix points on a continuum. SIT postulates that it depends on the situation, when an individuals' behavior is determined either by his personal or his social identity, while it is usually a mix of the two identities [10]. SIT states that individuals strive for positive self-assessment. To achieve this, individuals permanently compare themselves and the groups they belong to, to other meaningful groups, resulting in categorizing others to so-called in-groups and out-groups [10].

\subsection{Foundations of rivalry}

Rivalries are omnipresent in public life, like social, economic, religious, geographic, business or sporting rivalries [12]. Nonetheless, researchers have not been treating rivalry as a specific phenomenon in the context of competition. The term rival was more a synonym for descriptions as "disliked competitor" [13].

In recent years, researchers have begun to understand rivalry as more than just a "state of opposing goals or contested resources" [14]. In contrast to former research, rivalry can be understood as a subjective construct and a special relationship between two competitors with a higher meaning to the respective competitors [15]. Though, rivalry is sometimes based on rational attributes it more often reflects pure subjective bias towards another brand [12].

Havard et al. [16] see in a rivalry a ,fluctuating adversarial relationship existing between two teams, players, or groups of fans, gaining significance through on-field competition, on-field or off-field incidences, proximity, demographic makeup, and/or historical occurrence(s)“".

Tyler and Cobbs [17] base their understanding of rivalry on SIT and define a "rival group as a highly salient out-group that poses an acute threat to the identity of the in-group or to in-group members' ability to make positive comparisons between their group and the out-group."

First research on rivalry that share the same approach was conducted in the field of international conflicts and the fight for territories [18].

Research indicates that rivalries have positive as well as negative consequences. On the one hand, rivalries offer platforms for people with different cultural backgrounds and experiences to interact and therefore reduce barriers [19]. Moreover, rivalries offer entertainment and excitement for a huge number of persons [20]. The media also utilizes the increased attention to build up and influence rivalries [21].

On the other hand, rivalries foster bias, stereotyping and strange behaviors, that can, in the extreme, result in violent action or hostility [12]. Especially in sports, the relationship of violence and rivalry is not stated clearly in the literature. On the one side, Fans with high team identification seem to be willing to bribe or even hurt the opponents' players and coaches to influence teamsuccess $[22,23,24]$. On the other side, there was not found any relationship between fan aggressions and rivalry [25]. The so-called Schadenfreude - the German 
word for a feeling by a person who experience pleasure by the failure of another person/group/object- was identified by highly identified fans toward a hatred rival [13].

In the context of brand communities, outgroup discrimination was discovered as a result from the relationship between identification and intergroup stereotyping [26]. Thompson and Sinha [27] examined brand communities and the consequences of a membership for the loyalty, both within and across rival brand communities resulting in a sense of "oppositional loyalty". Across four studies Kilduff et al. [14] observed that rivalry fosters greater unethical behavior than nonrival competition. They postulate three major findings: first, competitions against rivals are more important to the sense of self-worthiness of individuals. Second, rivalry promotes individuals' focus on winning and less on the way to the victory. Third, they identify rivalry as a determinant of unethical behavior [14].

Studies also revealed that rivalries influence the behavior of fans. The perception of a rivalry is dependent on the identification with a team [28]. Thus, fans even visit matches of the respective rival when they believe they could influence the outcome of the game with their behavior [29]. Levine et al. [30] examined the role of social identity and the willingness to help an unknown person. They detected that people rather help a person when the person wears a shirt of the own team than when the person wears something neutral or even a shirt of the rival.

While most of the before mentioned studies focused on "the dark side" of rivalry, Berendt and Ulrich [31] widely confirmed their developed model which integrates both the positive and negative consequences on team sports consumer's self-concept, postulating that rivalries has a positive impact on perceived group distinctiveness, public collective self-esteem and perceived in-group cohesion.

In economics, the consequences of a sponsorship for fans of a rival were examined. Fans of the respective rival had greater awareness of the sponsor but also the attitude towards the sponsor was negatively influenced [32]. Moreover, rivalries are an attractive platform to place advertising [33].

Those studies mentioned all examined rivalries and their consequences. The question, which factors determine why a competitor becomes a rival remained unanswered. Two investigations have tried to determine those factors. The first researchers to do so were Kilduff et al. [15]. In their model they link the influencing factors of a rivalry with the performance of decision makers. They deduce three factors from the literature: similarity, repeated competition and competitiveness. They postulate that a rivalry increases the motivation of an employee and therefore the performance. They tested their model in the context of American College Basketball teams and the results confirmed their assumptions [15].

Building up on the work of Kilduff et al. [15], Tyler and Cobbs [17] investigated the perception of rivalries by fans and identified through a factor analysis three broad categories: conflict, peer and bias. The dimension 'conflict' derives from the competition between groups. The conflict on the field generates a symbolic conflict between the fans. The dimension conflict is determined by five factors: frequency of competition, parity (historical), parity (recent), defining moment, and starfactor. 'Peer' contains those factors that arise because a competitor is very comparable with the own team but nonetheless delineates oneself from the other team. The dimension is represented by the factors geography, cultural similarity, and competition for personnel. The last dimension "bias"" emerges because individuals may overrate certain aspects and includes the factors cultural differences, relative dominance and unfairness [17].

\subsection{Rivalry between smartphone manufacturers}

There are several relationships that come to mind when we think about rivalries in IS: Mac vs. PC, Apple vs. Windows, iOS vs. Android, Apple vs. Samsung.

Nonetheless, in the field of information systems, research which integrates the users as humans in the socio-technical system has been scarce. In the beginning of this century Lamb and Kling [34] pointed out that the traditional notion of users is not broad enough for the complex social reality of organizational computing.

They highlighted the importance of contextual and environmental factors and noted that users of IS are socially embedded in networks of relationships that mobilize the exchange of information and the use of IS. The call of Lamb and King [34] is today even more relevant because of users' integration of IS into their everyday life. This leads to fundamental changes concerning how users interact with computing devices and systems [35].

Regarding the construct of rivalry, still few research has been done. When scholars have conducted studies they focused rather on the consequences of rivalry then on the antecedents.

Positive consequences rarely have been postulated by scholars. Only Berendt and Ulrich [36] observed in a smartphone consumption setting that, as a direct effect, a higher perceived brand rivalry intensity leads to positive and significant perceived group distinctiveness, public collective self-esteem and perceived in-group cohesion. Moreover, one can conclude that users may benefit from rivalries by its impact on the markets. For example, among mobile communication and information technologies, the velocity of competition 
entails a huge amount of new products, new technical features and new functionalities, both on the hardware and on the software side [37].

Negative attitudes and actions towards a rival brand and their users were systematically investigated by Hickman and Ward [26]. They observed that in dependency of their identification with the brand users tend to communicate negatively about a rival brand provoked by a sense of inter-group rivalry [26].

Muniz and O'Guinn [38] as well as Belk and Tumbat [39] observed the so-called "oppositional brand loyalty" (= consumers with strong affinity for a brand unite in a strong dislike against the brand's rivals) among Mac users and their dislike for rival Microsoft.

Research in other fields already has discovered that the perception of a rivalry leads to bias, stereotyping and strange behavior $[14,16,36]$.

Some of these behaviors have been observed in the context of information systems, too. In a study in which apple and PC users were compared, it was observed that respondents with a higher identification with the brand had the tendency to rate their own brand better than the rivals brand. They evaluated users of their brand as more competent and more 'warm' than users of rival brands [26].

Phillips-Melancon and Dalakas [40] examined brand rivalry and consumers' Schadenfreude in the case of apple users. They contributed two main findings to the existing literature. First, highly identified apple users tend to perceive Schadenfreude on destructive incidents to entities associated with Microsoft. Second, there seem to exist some groups of consumers who are (attitudinally) harmful against other companies [40]. These results confirm the findings of Hickman and Ward [26] who found evidence of Apple users experiencing Schadenfreude after receiving fictitious news about Microsoft having IT-security troubles.

While several scholars have begun to understand the consequences of a rivalry, yet the determinants of those rivalries remain unstudied. Former research in other disciplines has detected several antecedents of rivalry $[15,17]$. By supporting the idea of Kilduff et al. [15] rivalry is a cognitive construct and depends on the relationship between the two actors - we think that the perceived importance of each rivalry antecedent differs between smartphone users who own smartphones from different manufacturers. In other words, we think that the group of owners of, for example, an Apple- device differ from the group of owners of a Samsung-device in the way they perceive the different antecedents of rivalry due to their characteristics as members of the social group 'owner of an apple smartphone'.

While in other disciplines, for example in sports, the on-field competition acts like a substitute for the delineation between two groups that differ in a specific category, we ask the question whether the same is true for rivalries in information systems.

Consequently, we investigate the relationship between the user and its smartphone manufacturer. This relationship is investigated by the construct of identification. Therefore, we establish the research question:

To which extend do smartphone users identify themselves with their smartphone manufacturer and are there differences between the smartphone groups?

Drawing on this, we introduce the construct of rivalry in the field of IS. Therefore, we establish the research question:

Which factors of rivalry are the most important regarding the smartphone groups?

\section{Research method}

The aim of this study was to determine whether there is a difference in the understanding of rivalry and the antecedents of rivalry between smartphone users in dependency of their respective smartphonemanufacturer. As smartphones have become a strong part and determine our daily life [5], we chose the field of smartphone manufacturers to extent the existing rivalry literature. We examine whether the rivalry factors of Tyler and Cobbs [17] can be applied in the field of information systems. Therefore, we conducted an online survey with smartphone users as participants.

The survey consisted of three parts. In the first part, we asked the participants to choose the manufacturer of their smartphone and to assess their identification with the same. Identification was measured with eight items $(\alpha=.856)$ which were developed by Tyler and Cobbs [17] and Bhattacharya et al. [41]. One item was removed because of poor indicator reliability ("I like using merchandise from..."). Table 1 shows the remaining seven items.

Table 1. Identification items

\begin{tabular}{|ll|}
\hline Identification Items & Mean (SD) \\
\hline I identify with... & $2,85( \pm 1,75)$ \\
\hline $\begin{array}{l}\text { I am very interested, what others } \\
\text { think of X. }\end{array}$ & $2,39( \pm 1,41)$ \\
\hline $\begin{array}{l}\text { When someone praises X, it feels } \\
\text { like a personal compliment. }\end{array}$ & $2,32( \pm 1,57)$ \\
\hline $\begin{array}{l}\text { When someone criticizes X, it } \\
\text { feels like a personal insult. }\end{array}$ & $2,07( \pm 1,37)$ \\
\hline $\begin{array}{l}\text { When X succeeds, it feels like a } \\
\text { personal success. }\end{array}$ & $2,07( \pm 1,44)$ \\
\hline $\begin{array}{l}\text { If a story in the media criticized } \\
\text { X, I would feel embarrassed. }\end{array}$ & $1,90( \pm 1,31)$ \\
\hline
\end{tabular}


When I think about X, I usually

think "we" rather than "they".

$1,85( \pm 1,48)$

In the second part, the participants chose the smartphone manufacturer that is from their view the biggest rival of their respective smartphone manufacturer. Afterwards, they assessed the importance of each of the eleven antecedents of rivalry and their meaning to their chosen rivalry. For example, they should evaluate whether recent success, the geographical situation or cultural differences between the two brands determine the rivalry. We used the antecedents of rivalry from Tylor and Cobbs [17] and adjusted the phrasing for the context of rivalries between smartphone manufacturers. Table 2 displays the items used for each antecedent.

Table 2. Antecedents of rivalry

\begin{tabular}{|c|c|}
\hline Rivalry element & Item \\
\hline Recent Parity & $\begin{array}{l}\mathrm{X} \text { and } \mathrm{Y} \text { had comparable } \\
\text { success within the last } \\
\text { years. }\end{array}$ \\
\hline Parity- Historical & $\begin{array}{l}\mathrm{X} \text { and } \mathrm{Y} \text { had comparable } \\
\text { success since market entry. }\end{array}$ \\
\hline Cultural Difference & $\begin{array}{l}\text { Y has different values than } \\
\text { X. }\end{array}$ \\
\hline Relative Dominance & $\begin{array}{l}\text { Y leads competition for } \\
\text { years and } \mathrm{X} \text { aspires to } \\
\text { overcome the success of } \mathrm{Y} \text {. }\end{array}$ \\
\hline $\begin{array}{l}\text { Frequency of } \\
\text { Competition }\end{array}$ & $\begin{array}{l}\text { The amount of product } \\
\text { launches of Y. }\end{array}$ \\
\hline $\begin{array}{l}\text { Competition for } \\
\text { Personnel }\end{array}$ & $\begin{array}{l}\mathrm{Y} \text { attracts the same } \\
\text { employees/ managers as X. }\end{array}$ \\
\hline Star Factor & $\begin{array}{l}\text { Extraordinary individuals } \\
\text { are connected to Y. }\end{array}$ \\
\hline Unfairness & $\begin{array}{l}\text { Y gets a preferential } \\
\text { treatment by governance/ } \\
\text { tester/ media/ etc. } \\
\text { compared to X. }\end{array}$ \\
\hline Cultural Similarity & $\begin{array}{l}\text { X shares the same values } \\
\text { with Y. }\end{array}$ \\
\hline Geography & $\begin{array}{l}\text { The headquarters of } \mathrm{X} \text { and } \\
\mathrm{Y} \text { are located close to each } \\
\text { other. }\end{array}$ \\
\hline Defining Moment & $\begin{array}{l}\text { A specific incident (e.g. } \\
\text { campaigns/ litigations) } \\
\text { between } \mathrm{X} \text { and } \mathrm{Y} \text {. }\end{array}$ \\
\hline
\end{tabular}

For both, part one and two, we measured the answers on a seven point Likert scale from 1 (= never/ no meaning/ strongly disagree) to 7 (= always/ very important/ strongly agree). Moreover, to give participants another alternative in case they could not assess the meaning of a factor and to prevent a random answer, they could choose "I can't assess" as additional possible answer. In the third part, we asked for general and demographic information such as gender, age and education. We investigated the identification of the participants with their respective smartphone manufacturer. Afterwards we analyzed the importance of each factor for the respective rivalry. Finally, we cross-checked if the results vary depending on the brand that the participant is using (i.e. Apple vs. Samsung). Therefore, we conducted a rank correlation analyses for the respective variables.

The survey started in March 2017 and was online for approximately four weeks. In total, we received 351 responses. After excluding data sets where the majority of questions was left unanswered, we ended up with 328 responses. $39.6 \%$ of the participants were female and the mean age of the participants was $25.19( \pm 6,19)$.

First, we asked the participants to choose the manufacturer of their respective smartphone. Figure 1 shows the distribution of smartphone manufacturers within the participants.

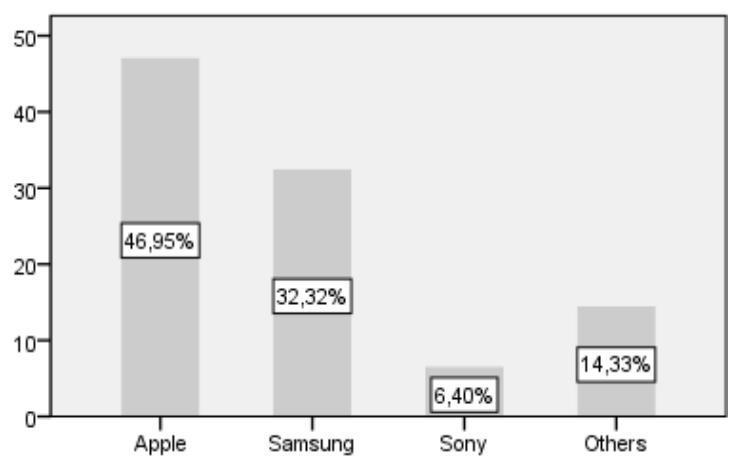

Figure 1. Distribution of smartphones

Nearly $80 \%$ of the participants had either a smartphone from Apple or Samsung. 21 participants or $6.38 \%$ were owner of a smartphone from Sony. The group Others includes all other brands such as Huawei (13 Participants), LG (8), HTC (5) or not named brands (16). The former giants Nokia (3) and RIM (1) made together only $1,2 \%$ of the participants.

\section{Results and discussion}

First, we asked the participants to evaluate their identification with their respective smartphone manufacturer. Overall, the participants do not seem to build a strong bond with their smartphone manufacturer $(2,20( \pm 1,09))$. This is a quite low identification level compared to other studies $[31,40]$.

To determine whether there were differences in the identification in dependency of the smartphone manufacturer, we conducted a Kruskal-Wallis-Test. 
Identification was significantly affected by the smartphone manufacturer, $\mathrm{H}(3)=17,710, \mathrm{p}=.001$. Even if smartphone users in general do not seem to identify themselves with their smartphone manufacturer, Apple users identify themselves significantly stronger with their smartphone manufacturer than Samsung users do. The results of follow-up pairwise comparisons between smartphone manufacturers with adjusted $\mathrm{p}$-values is shown in table 3.

Table 3. Pairwise comparison of groups

\begin{tabular}{|l|rr|}
\hline Rivalry & Adj. $p$ & $r$ \\
\hline Samsung - Others & .596 & $-0,133$ \\
\hline Samsung - Sony & .705 & $-0,139$ \\
\hline Samsung- Apple & .000 & 0,260 \\
\hline Others - Sony & 1.000 & 0,039 \\
\hline Others - Apple & .892 & 0,102 \\
\hline Sony - Apple & 1.000 & 0,051 \\
\hline
\end{tabular}

This is not surprising, as scholars recently have detected that iPhone users see their phone more likely as a status object and, in comparison, Android-driven users are less interested in wealth and status [9].

In the second part of the study, we asked the participants to name the biggest rival of their smartphone manufacturer. Table 4 shows the most often named rivalries (minimum of 3 nominations, $n=228$ ).

Table 4. Rivalries named by participants

\begin{tabular}{|ccccc|}
\hline A & B & $\sum$ & $\mathbf{A} \rightarrow \mathbf{B}$ & $\mathbf{B} \rightarrow \mathbf{A}$ \\
\hline Apple & Samsung & 243 & 144 & 99 \\
\hline Sony & Samsung & 13 & 12 & 1 \\
\hline Huawei & Samsung & 10 & 8 & 2 \\
\hline Sony & Apple & 8 & 6 & 2 \\
\hline Huawei & Apple & 6 & 4 & 2 \\
\hline HTC & Samsung & 6 & 4 & 2 \\
\hline Other & Samsung & 6 & 6 & 0 \\
\hline LG & Samsung & 6 & 5 & 1 \\
\hline Other & Apple & 5 & 3 & 2 \\
\hline Apple & HTC & 3 & 2 & 1 \\
\hline Other & Other & 3 & 3 & 0 \\
\hline
\end{tabular}

Both Apple as well as Samsung users determined the rivalry between each other as the most prominent rivalry between smartphone manufacturers. Another remarkable notice: the users of smartphone manufacturers in the hunt of the 'Big Two' (Apple and
Samsung) all identified either Samsung or Apple as their biggest rival. While users of Huawei, HTC and LG identified Samsung as their biggest rival, the users of smartphones from Sony where divided into two groups. Of the 21 participants with a smartphone from Sony more than half of them identified Samsung as their biggest rival (12). 6 participants chose Apple as biggest rival.

The participants were then asked to evaluate the importance of eleven antecedents of rivalry to better understand what factors influence the development of a rival. Table 5 shows the mean and the standard deviation of the different antecedents of rivalries between smartphone manufacturers.

Table 5. Descriptive statistics of the rivalry factors

\begin{tabular}{|ll|}
\hline Rivalry elements & Mean $( \pm$ SD) \\
\hline Recent Parity & $4,7( \pm 1,56)$ \\
\hline Historical Parity & $4,7( \pm 1,76)$ \\
\hline Cultural Difference & $4,3( \pm 1,64)$ \\
\hline Relative Dominance & $4,3( \pm 2,02)$ \\
\hline Frequency of Competition & $4,2( \pm 1,71)$ \\
\hline Competition for Personnel & $4,0( \pm 1,80)$ \\
\hline Defining Moment & $3,9( \pm 1,95)$ \\
\hline Star Factor & $3,4( \pm 2,01)$ \\
\hline Unfairness & $3,3( \pm 1,82)$ \\
\hline Cultural Similarity & $3,3( \pm 1,50)$ \\
\hline Geography & $2,0( \pm 1,50)$ \\
\hline
\end{tabular}

The distribution over all groups determines the recent and historical parity as the two most important factors. Participants valued those two factors between somewhat important and important. This confirms partially the results of Tylor and Cobbs [17], who ranked recent and historical parity as third respectively fourth most important factor, and the results of Kilduff et al. [15] who also stress the importance of historical and recent status. As supposed due to the high velocity of the market, the frequency of competition does have an impact on the perception of rivalry in the field of smartphones [37]. Geography was rated low by the participants. This is contradictory to related research $[15,17]$, where the influence of the geographical location has been valued higher.

We conducted another Kruskal-Wallis test to determine whether there were differences in the evaluation of the importance of the antecedents of rivalry between the different user groups. In dependency of the groups, 8 of 11 factors differ significantly. Table 6 shows which antecedents were evaluated 
differently in dependency of the smartphone manufacturer.

Table 6. Differences in meaning for rivalry

\begin{tabular}{|l|rrr|}
\hline \multicolumn{1}{|c}{ Factor } & $\mathrm{dF}$ & \multicolumn{1}{c|}{$\mathrm{z}$} & \multicolumn{1}{c|}{$\mathrm{p}$} \\
\hline Recent Parity & 3 & 20,934 & .000 \\
\hline Historical Parity & 3 & 8,26 & .041 \\
\hline Cultural Difference & 3 & 9,814 & .020 \\
\hline Relative Dominance & 3 & 51,148 & .000 \\
\hline Frequency of Competition & 3 & 1,293 & .731 \\
\hline Competition for Personnel & 3 & 4,128 & .248 \\
\hline Star Factor & 3 & 62,566 & .000 \\
\hline Unfairness & 3 & 15,426 & .001 \\
\hline Cultural Similarity & 3 & 13,054 & .005 \\
\hline Defining Moment & 3 & 16,077 & .001 \\
\hline Geography & 3 & 3,601 & .308 \\
\hline
\end{tabular}

The results show that for smartphone users it depends on their smartphone manufacturer, which factors are important for a rivalry. This confirms recent research that examines the relationship between an individual's characteristics and the decision to make a specific smartphone manufacturer to become a part of the respective everyday life $[5,6,9]$.

From a perspective of SIT, individuals strive for positive self-assessment and compare themselves and the group they belong to with other salient out-groups [10]. The individuals tend to use those factors that help them to achieve a positive outcome of the comparison. The further conducted follow-up tests support this assumption and demonstrate in detail which of the groups differentiate significantly. The results of the pairwise comparison between the groups are shown in table 7.

Table 7. Pairwise comparison for each factor (only significant results are presented)

\begin{tabular}{|c|c|c|}
\hline Rivalry & $\mathrm{p}$ & $\mathrm{r}$ \\
\hline \multicolumn{3}{|c|}{ Recent Parity } \\
\hline Apple vs. Other & .050 & .215 \\
\hline Samsung vs. Other & .001 & .341 \\
\hline Samsung vs. Sony & .011 & .295 \\
\hline \multicolumn{3}{|c|}{ Cultural Difference } \\
\hline Samsung vs. Other & .025 & .261 \\
\hline \multicolumn{3}{|c|}{ Relative Dominance } \\
\hline Apple vs. Sony & .016 & .254 \\
\hline Apple vs. Samsung & .000 & .476 \\
\hline
\end{tabular}

Apple vs. Other

.026

.227

\begin{tabular}{lcc}
\multicolumn{4}{c}{ Star-Factors } \\
Apple vs. Samsung & .000 & .531 \\
Samsung vs. Sony & .034 & .261 \\
Samsung vs. Other & .003 & .322 \\
& Unfairness \\
Apple vs. Samsung & .001 & .297 \\
Cultural Similarity \\
Apple vs. Sony & .024 & .239 \\
\multicolumn{4}{c}{ Moment } \\
Apple vs. Other & .003 & .274 \\
Samsung vs. Other & .006 & .314 \\
\hline
\end{tabular}

Pairwise comparisons indicate, that, for example, users of the most often mentioned smartphone manufacturers Apple and Samsung perceive antecedents of rivalry differently. Apple users rate the meaning of star-factors significantly higher than Samsung users do, assisting them to accomplish positive self-assessment. The same can be observed for Samsung users and the factor relative dominance.

\section{Conclusion}

In this paper we investigated the inside-out groupperspective of users regarding their SMD-affiliation. We assume that users distance themselves from other user groups because of the device they use. We provided a survey-based study concerning the identification and the rivalry between smartphone users.

Our results demonstrate that in dependency of group affiliation users differ in their identification level as well as in their perception of rivalry. While there was in general a relative low level of identification with the respective smartphone manufacturer, we observed that Apple users tend to higher identification than users of other smartphone manufacturer. This stands in line with recent observations, that iPhone-user see their smartphone as a status object [9].

Moreover, we could determine that group-affiliation determines the evaluation of the factors that influence the formation of a rivalry. As SIT states, individuals strive for a positive self-assessment and therefore conduct comparisons against other groups [10]. In our study, groups differed significantly in 8 of 11 factors regarding the evaluation of the antecedents of rivalry. Further analysis demonstrated that each group rated other factors as important for the respective rivalry.

The study is subject to several limitations due to the nature of our research. Firstly, the sample size does not represent all age groups because of the large number of 
students. Moreover, we did not consider culture bound issues as the sample only consists of German users of SMD. In addition, we only have very general information on the demographic characteristics of our respondents, which limits the ability to relate app consumers' information seeking behavior to demographic characteristics. Furthermore, it is questionable whether survey-research is the best form to research identification.

As rivalries are omnipresent in our everyday life, further research is necessary to better understand the phenomenon in IS. Moreover, a mixed-model approach could be beneficial to achieve deeper insights in the construct of rivalry (e.g. item development) and the understanding of social groups in IS.

\section{References}

[1] Yoo, Y., "Computing in Everyday Life: A Call for Research on Experiential Computing", MIS Quarterly, 34(2), 2010, pp. 213-231.

[2] Apple Inc., “Apple Trademark List”, http://https://www. apple.com/legal/intellectual-property/trademark/appletmlist .html, 2017.

[3] Gartner, "Global market share held by smartphone operating systems from 2009 to 2016", https://www. statista.com/statistics/263453/global-market-share-held-bysmartphone-operating-systems/.

[4] Markowetz, A., K. Błaszkiewicz, C. Montag, C. Switala, and T.E. Schlaepfer, "Psycho-informatics: Big Data shaping modern psychometrics", Medical hypotheses, 82(4), 2014, pp. 405-411.

[5] Sarwar, M. and T.R. Soomro, "Impact of Smartphone's on Society", European Journal of Scientific Research, 98(2), 2013, pp. 216-226.

[6] Nass, C.I. and C. Yen, The man who lied to his laptop: What we can learn about ourselves from our machines, Current; Turnaround [distributor], New York, London, 2012.

[7] Lane, W. and C. Manner, "The Impact of Personality Traits on Smartphone Ownership and Use", International Journal of Business and Social Science, 2(17), 2011.

[8] Hooi Ting, D., S. Fong Lim, T. Siuly Patanmacia, C. Gie Low, and G. Chuan Ker, "Dependency on smartphone and the impact on purchase behaviour", Young Consumers, 12(3), 2011, pp. 193-203.

[9] Shaw, H., D.A. Ellis, L.-R. Kendrick, F. Ziegler, and R. Wiseman, "Predicting Smartphone Operating System from Personality and Individual Differences", Cyberpsychology, behavior and social networking, 19(12), 2016, pp. 727-732.

[10] Tajfel, H. and J.C. Turner, "An integrative theory of intergroup conflict.", in The social psychology of intergroup relations, W.G. Austin, Editor. 1979. Brooks/Cole: Monterey, Calif.
[11] Hogg, M.A., "Social Identity Theory", in Contemporary social psychological theories, P.J. Burke, Editor. 2006. Stanford Social Sciences: Stanford, Calif.

[12] Ewing, M., P.E. Wagstaff, and I.H. Powell, "Brand rivalry and community conflict", Journal of Business Research, 66(1, (1)), 2013, pp. 4-12.

[13] Dalakas, V. and J.P. Melancon, "Fan identification, Schadenfreude toward hated rivals, and the mediating effects of Importance of Winning Index (IWIN)", Journal of Services Marketing, 26(1), 2012, pp. 51-59.

[14] Kilduff, G.J., A.D. Galinsky, E. Gallo, and J.J. Reade, "Whatever It Takes to Win: Rivalry Increases Unethical Behavior", Academy of Management Journal, 59(5), 2016, pp. 1508-1534.

[15] Kilduff, G.J., H.A. Elfenbein,,and B.M. Staw, "The Pyschology of Rivalry: A Relationally Dependent Analysis of Competition", Academy of Management Journal, 53(5), 2010, pp. 943-969.

[16] Havard, C.T., D.P. Gray, J. Gould, L.A. Sharp, and J.J. Schaffer, "Development and validation of the Sport Rivalry Fan Perception Scale (SRFPS)", Journal of Sport Behaviour, 36(1), 2013, pp. 45-65.

[17] Tyler, B.D. and J.B. Cobbs, "Rival conceptions of rivalry: Why some competitions mean more than others", European Sport Management Quarterly, 15(2), 2015, pp. 227-248.

[18] Goertz, G. and P.F. Diehl, "Enduring rivalries: theoretical constructs and empirical patterns", International Studies Quarterly, 37, 1993, pp. 147-171.

[19] Lee, M.J., "From Rivalry to Hostility Among Sports Fans", Quest, 37(1), 1985, pp. 38-49.

[20] Armstrong, G. and R. Giulianotti, eds., Fear and loathing in world football, Berg, Oxford, 2001.

[21] Benkwitz, A. and G. Molnar, "Interpreting and exploring football fan rivalries: an overview", Soccer \& Society, 13(4), 2012, pp. 479-494.

[22] Wann, D.L., J.D. Carlson, and M.P. Schrader, "The Impact of Team Identification on the Hostile and Instrumental Verbal Aggression of Sport Spectators", Journal of Social Behaviour and Personality, 14(2), 1999, pp. 279286.

[23] Wann, D.L., J.L. Hunter, J.A. Ryan, and L.A. Wright, "Team Identification and Willingness to Consider Illegally Assisting Teams", Social Behaviour and Personality, 29(6), 2001, pp. 531-536.

[24] Wann, D.L., G. Haynes, B. McLean, and P. Pullen, "Sport Team Identification and Willingness to Consider Anonymous Acts of Hostile Aggression", Aggressive Behaviour, 29, 2003, pp. 406-413.

[25] Dimmock, J.A. and J.R. Grove, "Relationship of Fan Identification to Determinants of Aggression", Journal of Applied Sport Psychology, 17, 2005, pp. 37-47. 
[26] Hickman, T. and J. Ward, "The Dark Side of Brand Community: Inter-Group Stereotyping, Trash Talk, and Schadenfreude", Advances in Consumer Research, 34, pp. 314-319.

[27] Thompson, S.A. and R.K. Sinha, "Brand Communities and New Product Adoption:The Influence and Limits of Oppositional Loyalty", Journal of Marketing, 72(6), 2008, pp. $65-80$

[28] Havard, C.T., D.L. Wann, and T.D. Ryan, "Investigating the impact of conference realignment on rivalry in intercollegiate athletics", Sport Marketing Quarterly, 22(4), 2013, pp. 224-234.

[29] Sierra, J.J., H.A. Taute, and r.S. Heiser, "Personal Opinions and Beliefs as Determinants of Collegiate Football Consumption for Revered and Hated Teams", Sport Marketing Quarterly, 19(3), 2010, pp. 143-153.

[30] Levine, M., A. Prosser, D. Evans, and S. Reicher, "Identity and Emergency Intervention: How Social Group Membership and Inclusiveness of Group Boundaries Shape Helping Behaviour", Personality and Social Psychology Bulletin, 31(4), 2005, pp. 443-453.

[31] Berendt, J. and S. Ulrich, "Enemies with benefits: The dual role of rivalry in shaping sports fans' identity", European Sport management quarterly : ESMQ, 16(5, (12)), 2016, pp. 613-634.

[32] Davies, F., C. Veloutsou, and A. Costa, "Investigating the influence of a joint sponsorship of rival teams on supporter attitudes and brand preferences", Journal of Marketing Communications, 12(1), 2006, pp. 31-48.
[33] Boyd, T.C. and T.C. Krehbiel, "Promotion Timing in Major League Baseball and the Stacking Effects of Factors That Increase Game Attractiveness", Sport Marketing Quarterly, 12(3), 2003, pp. 173-183.

[34] Lamb, R. and R. Kling, "Reconceptualizing Users as Social Actors in Information Systems Research", MIS Quarterly, 27(2), 2003, pp. 197-236.

[35] Venkatesh, V., J.Y.L. Thong, and X. Xu, "Consumer Acceptance and Use of Information Technology: Extending the Unified Theory of Acceptance and Use of Technology", MIS Q, 36(1), 2012, pp. 157-178.

[36] Berendt, J. and S. Ulrich, "Marketing, Get Ready to Rumble: Why Consumers Appreciate Brand Rivalries", Advances in Consumer Research, 44, 2016, pp. 390-391.

[37] Cecere, G., N. Corrocher, and R.D. Battaglia, "Innovation and competition in the smartphone industry: Is there a dominant design?", Telecommunications Policy, 39(3-4), 2015, pp. 162-175.

[38] Muniz, A.M. and T.C. O'Guinn, "Brand Community", Journal of Consumer Research, 27(4), 2001, pp. 412-432.

[39] Belk, R.W. and G. Tumbat, "The Cult of Macintosh", Consumption Markets \& Culture, 8(3), 2005, pp. 205-217.

[40] Phillips-Melancon, J. and V. Dalakas, "Brand Rivalry and Consumers' Schadenfreude: The Case of Apple", Services Marketing Quarterly, 35(2), 2014, pp. 173-186.

[41] Bhattacharya, C.B., H. Rao, and M.A. Glynn, "Understanding the Bond of Identification: An Investigation of Its Correlates among Art Museum Members", Journal of Marketing, 59(4), 1995, p. 46. 